\title{
DIREITO AMBIENTAL E SUSTENTABILIDADE
}

\author{
Elenise Felzke Schonardie ${ }^{1}$
}

\section{RESUMO}

O presente texto tem por objetivo apresentar alguns dos fatores que levaram ao surgimento e à consolidação do direito ambiental no cenário sóciojurídico brasileiro, a partir do surgimento dos interesses transindividuais e do reconhecimento do ambiente como bem jurídico. Considera, além disso, as imbricações do direito ambiental com o direito ao desenvolvimento e a ideia de sustentabilidade ambiental, ambos entendidos como direitos fundamentais, bem como, propõe algumas reflexões a partir da análise da teoria das necessidades. ${ }^{2}$

Palavras-chave: Direito ambiental. Sustentabilidade. Teoria das necessidades.

\section{DIREITO AMBIENTAL E O AMBIENTE COMO BEM JURÍDICO}

A relação homem-natureza, ao longo dos tempos, passou por diversas fases. Num primeiro momento, essa relação era de temor, pois os homens desconheciam não apenas os fenômenos naturais, mas também os próprios bens ambientais, no sentido que os concebemos na contemporaneidade. Após, numa segunda fase, passamos para a dominação e a exploração da natureza e, para isso, os indivíduos precisavam conhecê-la e, do mesmo modo, fazê-lo em relação aos e seus elementos. Hodiernamente, encontramo-nos em uma terceira fase, a da criação da natureza, com os avanços das ciências, somos capazes de recriar a natureza.

Ao passar dos anos, a ação do homem sobre a natureza, dá-se por meio do domínio e da exploração. $O$ crescimento e o desenvolvimento das sociedades têm demonstrado serem imperativos projetos, programas e planos de ocupação e organização do espaço, isso porque, durante muito tempo, não havia planos de desenvolvimento (social, econômico e cultural) e de conservação da natureza (e do ambiente).

Com o desenvolvimento das sociedades, surgiram os problemas ambientais, como o esgotamento de recursos naturais, devastações, doenças, epidemias, pobreza, etc. Esses problemas, num primeiro momento, eram vistos apenas como locais. Não havia a dimensão transfronteiriça que as consequências dos problemas ambientais, tidos como "locais", pudessem impactar negatividade à região. Assim, a busca por resolução dos danos ambientais era, a princípio, apenas local.

Indubitavelmente, toda e qualquer intervenção do indivíduo sobre o ambiente gera impacto, alguns maiores, outros menores. No entanto, a intervenção do homem no ambiente também pode ocorrer para fins de 
melhoramento da qualidade ambiental. Todavia, os resultados da intervenção nociva do homem sobre o ambiente, ao longo dos tempos, fizeram eclodir movimentos isolados de proteção do ambiente. Esses movimentos surgiram em lugares diferentes, em tempos distintos e, geralmente, por motivos díspares (mas com um objetivo em comum - a proteção do ambiente e de seus recursos naturais).

Muito além da edição de textos de lei versando sobre a proteção de determinados bens naturais - alguns ampliando o grau de proteção, outros 0 reduzindo ou suprimindo -, a discussão social sobre as questões ambientais passou a fazer parte das agendas locais, regionais, nacionais e internacionais, desencadeando o aparecimento de um número significativo de institutos, fundações e ONGs, cujos objetivos são direcionados à proteção de ecossistemas, à preservação de espécies e à propagação da ideia de sustentabilidade ecológica.

No século 20, várias foram as tentativas de direcionamento das questões ambientais, não havia, porém, uma diretiva mundial definida para conter ou reduzir a degradação ambiental. Em junho de 1972, na cidade de Estocolmo foi realizada a primeira grande conferência mundial para tratar das questões ambientais, voltadas para o desenvolvimento, a sustentabilidade e a manutenção da vida com qualidade na Terra - reação ao desenvolvimento industrial e econômico centralizado, exploração de países desenvolvidos sobre os subdesenvolvidos (hoje, referidos como em desenvolvimento).

A Declaração do Meio Ambiente, adotada pela Conferência das Nações Unidas, em junho de 1972, é composta de 26 princípios e constitui-se num prolongamento da Declaração Universal dos Direitos do Homem. Neste ponto, podemos fazer uma conexão entre os direitos do homem e o surgimento do direito ambiental considerado como ramo específico do direito. Isso porque, entendemos que a fruição dos homens e mulheres a um ambiente equilibrado constitui um direito fundamental a ser observado, como se constatará ao longo do texto.

Outro evento internacional de grande importância para o ambiente e as discussões internacionais acerca de uma possível proposta de sustentabilidade ambiental foi a RIO/92 - Conferência das Nações Unidas sobre o Meio Ambiente e Desenvolvimento -, realizada de três a 14 de junho de 1992, na cidade do Rio de Janeiro. Esse encontro resultou na elaboração de 27 princípios que apelam à cooperação internacional dos Estados para a tomada de atitudes e ações de controle ambiental. As nações devem apoiar e executar os programas e os instrumentos provenientes da observância daqueles princípios. O encontro de 1992, derivou a elaboração de outros acordos e documentos internacionais, os quais referimos: Convenção sobre o Clima; Convenção sobre a Biodiversidade; Declaração do Rio de Janeiro sobre Meio Ambiente e Desenvolvimento; Declaração dos Princípios sobre Florestas e Agenda 21. Este último, constitui-se em um plano de ação analítico para a realização do desenvolvimento sustentável no século 21. 
Um dos resultados da Convenção do Clima de 1992 foi a elaboração e a assinatura da Convenção Quadro, conhecida como Protocolo de Quioto, celebrada em dezembro de 1997, com a presença de 39 países desenvolvidos, que incluía metas e prazos relativos a redução ou a limitação das emissões futuras de dióxido de carbono e outros gases responsáveis pelo efeito estufa (Convenção-Quadro das Nações Unidas sobre Mudança do Clima, esse protocolo refere-se a Terceira Conferência - COP-3). O detalhe desse documento é que os programas de redução de emissão de $\mathrm{GEE}^{3}$ serão financiados por empresas de países desenvolvidos, para serem executados em países em desenvolvimento, como o Brasil, que tem a sua matriz produtiva centrada no setor agropecuário e em uma indústria incipiente e moderna.

Há que destacarmos ainda o Programa das Nações Unidas para o Meio Ambiente - PNUMA, adotado pela Assembleia-Geral da ONU, segundo Resolução 1.897. Esse programa intervém em três níveis; a saber: 1. avaliação do meio ambiente (avaliação e análise, pesquisa, troca de informações); 2. gestão do meio ambiente (fixação de objetivos e planificação, consultas e acordos internacionais); 3. medidas de sustentação (educação e formação profissional, informação, organização, financiamento, cooperação técnica). Em outras palavras, cabe-lhe por em ação os princípios da Declaração de Estocolmo, concernentes à responsabilidade dos Estados pelos danos ambientais. Frente a esses princípios internacionais de proteção ambientais, resta aos Estados a sua adoção em seus sistemas legais internos. Para tanto, cada Estado deve procurar observar os princípios da Declaração de Estocolmo e da Declaração do Rio, com relação às medidas de proteção, ao controle e ao desenvolvimento ambiental. Em face dessas novas e complexas situações e demandas da atualidade, há o desenvolvimento de uma área jurídica específica que se caracteriza pela sua transdisciplinaridade, o Direito Ambiental.

No Brasil, o Direito Ambiental, entendido como área especifica do direito, surge para regular, interpretar e resolver os conflitos sócio-ambientais emergentes na sociedade contemporânea. Isto é, o direito ambiental vem regular, exigir e sancionar as condutas lesivas ao ambiente que, em tese, deveriam ser de observação automática (ou natural) dos indivíduos.

Em seu aspecto objetivo, o Direito Ambiental consiste no conjunto de normas jurídicas disciplinadoras da proteção da qualidade do meio ambiente. Em sua condição de Ciência, o direito ambiental procura o conhecimento sistematizado das normas e princípios ordenadores da qualidade do meio ambiente. Lembrando sempre que o ser humano é a razão de toda a preocupação com o ambiente, pois, pretende-se garantir-lhe uma vida digna em um meio ecologicamente equilibrado.

Quanto ao conteúdo, o Direito Ambiental tem conteúdo multidisciplinar, isso porque se utiliza de institutos do direito administrativo, civil, constitucional, penal e internacional, entre outros, de áreas distintas e sua proteção é difusa, pois visa à proteção dos cidadãos e não de uma pessoa ou grupo determinado ou específico de pessoas, com o intuito de integrá-la com os demais elementos que formam o meio natural, artificial ou cultural. 
O Direito Ambiental é um Direito sistematizador, que faz a articulação da legislação, da doutrina e da jurisprudência concernentes aos elementos que integram o ambiente. Procura evitar o isolamento dos temas ambientais e sua abordagem antagônica. (...) O Direito Ambiental não ignora o que cada matéria tem de específico, mas busca interligar estes temas com a argamassa da identidade dos instrumentos jurídicos de prevenção e de reparação, de informação, de monitoramento e de participação. É em 'tema transversal'. (MACHADO, 2006, p. 149-150).

Essa transversalidade do direito ambiental apóia-se no imperativo de concepção da problemática ambiental que vai além de uma compreensão disciplinar. $\mathrm{E}$ a regulação dos bens e interesses pertinentes à questão do meio ambiente justifica-se pelo constante descumprimento de deveres (direitos), cujo objetivo é garantir aos indivíduos (homens e mulheres) um meio sadio e equilibrado, no qual possam desenvolver-se.

O reconhecimento do ambiente como bem jurídico tem seu início a partir do surgimento e reconhecimento dos interesses transindividuais. No entanto, o reconhecimento desses novos interesses, que ultrapassam a esfera meramente particular dos indivíduos, desenvolveu-se concomitantemente às transformações do Estado moderno e às questões relativas ao reconhecimento e à evolução dos direitos humanos.

Os direitos humanos, segundo Bobbio (1992, p. 30), nascem como direitos naturais e universais, desenvolvem-se como direitos positivos particulares (quando cada Constituição incorpora Declarações de Direito) para, finalmente, encontrarem a sua plena realização como direitos positivos universais. O que se deve ter como assente é o fato de que a ascensão dos direitos é fruto de lutas, que

os direitos são conquistados, às vezes, com barricadas, em um processo histórico cheio de vicissitudes, por meio do qual as necessidades e as aspirações se articulam em reivindicações e em estandartes de luta antes de serem reconhecidos como direitos (SACHS, 1998, p.156.).

Não podemos esquecer que o

direito é uma criação humana, e seu valor deriva, justamente, daquele que $o$ criou. $O$ que significa que esse fundamento não é outro, senão 0 próprio homem, considerado em sua dignidade substancial de pessoa, diante da qual as especificações individuais e grupais são sempre secundárias.(COMPARATO, 1998, p. 60).

Entendido como processo de construção histórica e social, o reconhecimento dos direitos humanos passou por fases distintas, as quais Bobbio (1992) denomina de gerações. Na primeira geração, identificamos os chamados direitos de liberdade civil e política. A segunda geração de direitos humanos foi alcançada pelo reconhecimento dos direitos sociais. Já na terceira geração, que, na concepção do doutrinador italiano, constitui uma categoria heterogênea e vaga, encontra-se o direito de viver num ambiente não poluído. Tal direito sequer poderia ter sido imaginado por ocasião da luta e do 
reconhecimento dos direitos de segunda geração, da mesma forma que estes não haviam sido cogitados por ocasião da promulgação dos direitos de primeira geração. Adiante nos escritos de Bobbio, hodiernamente, deparamo-nos frente a uma quarta geração de direitos, os relacionados ao código genético das espécies e, também, em uma já referida quinta geração, encontramos as questões concernentes ao espaço cibernético.

Nosso objeto centra-se nos direitos e nos interesses de terceira geração. Para além dos direitos de primeira e segunda geração, os direitos de terceira geração emergem como direitos de solidariedade que têm por destinatários o próprio gênero humano, na medida em que objetivam a compreensão da necessária preservação e conservação do ambiente e seus recursos naturais. Não buscam a imediata garantia ou a segurança individual, sequer a coletiva própria dos direitos de segunda geração, mas vão além na busca pela garantia da sobrevivência das espécies, da paz entre os povos, da manutenção de patrimônios comum à humanidade e do direito ao desenvolvimento progressivo, como expressão do prolongamento dos direitos humanos.

A complexidade das relações sociais decorrente do processo evolutivo, que foi desencadeado pela modernidade, e seus variados processos de modernização, pelos quais tem passado a sociedade ocidental, fizeram eclodir a proteção de interesses que transcendessem a individualidade, uma vez que os direitos e as garantias individuais já estavam teoricamente reconhecidos pelos Estados. As transformações das sociedades, no século 20 desencadearam o processo de luta e reconhecimento dos interesses transindividuais, por meio da consolidação dos direitos humanos de terceira geração. Estes direitos humanos de terceira geração, dentre os quais o direito de viver em um meio ambiente sadio e ecologicamente equilibrado, cujo conteúdo é genérico, têm como destinatário (determinado ou indeterminado) o gênero humano e sua proteção ou sua violação atinge esse conjunto indeterminado ou determinável de indivíduos.

No âmbito jurídico-legal brasileiro, muito embora a Constituição Federal de 1988 já tivesse elevado "o ambiente" à categoria de bem jurídico fundamental e destacado a relevância da proteção dos interesses transindividuais em vários dispositivos, além do artigo 225 e seus respectivos parágrafos, a definição legal dos interesses e direitos transindividuais só ocorreu com a publicação da Lei 8.078, em 1990, - o Código de Defesa do Consumidor.

A concepção jurídico-legal desses interesses e direitos transindividuais, elencada pelo artigo 81, da lei n. 8.078/90, abrange os chamados interesses e direitos difusos, os coletivos e os individuais homogêneos. Entendendo-se por interesses difusos, nos termos do artigo 81, inciso I, da lei, os "direitos ou interesses difusos, aqueles de natureza indivisível de que sejam titulares pessoas indeterminadas e ligadas por circunstância de fato", significando, pois, que a caracterização desses interesses dá-se pela indeterminabilidade dos titulares, a indivisibilidade do bem jurídico, a inexistência da relação jurídica de base e a existência de relação fática. 
A percepção dos problemas ligados ao meio ambiente engloba as questões pertinentes ao desenvolvimento, ou melhor, ao direito ao desenvolvimento orientado à sustentabilidade planetária, conjugando, nessa nova universalidade, as pretensões ligadas à saúde, ao trabalho, à paz, enfim, ao meio ecologicamente equilibrado.

Assim, podemos afirmar que a passagem do individual para 0 transindividual, do singular para 0 coletivo, não se faz mediante 0 aniquilamento do indivíduo mas, sim, inserindo-o numa dimensão comunitária e solidária, que tem por objetivo garantir a vida em um meio saudável e ecologicamente equilibrado. E, isso, deve ser lembrado e observado, diante da complexidade das relações de apropriação de recursos ambientais, de produção e de consumo em uma sociedade como a nossa.

\section{DO DIREITO AO DESENVOLVIMENTO E A IDEIA DE SUSTENTABILIDADE AMBIENTAL}

O direito ao desenvolvimento progressivo, seja econômico, seja social e cultural, garantido no art. 26 da Convenção Americana de Direitos Humanos Pacto de San José da Costa Rica refere que:

Os Estados-partes comprometem-se a adotar providencias, tanto de âmbito interno, como mediante cooperação internacional, especialmente econômica e técnica, a fim de conseguir progressivamente a plena efetividade dos direitos que decorrem das normas econômicas, sociais e sobre educação, ciência e cultura, constantes na Carta da Organizações dos Estados Americanos, reformada pelo Protocolo de Buenos Aires, na medida dos recursos disponíveis, por via legislativa ou por meios apropriados. (PIOVESAN, 2000, p. 412).

Do mesmo modo, o Protocolo Adicional à Convenção Americana sobre Direitos Humanos em matéria de Direitos econômicos, sociais e culturais (Protocolo de San Salvador), em seu artigo 11, especifica a necessidade de adoção de medidas de proteção ao ambiente.

Direito a um meio ambiente sadio - 1 . Toda pessoa tem o direito de viver em meio ambiente sadio e a contar com os serviços públicos básicos. 2. Os Estados Partes promoverão a proteção, preservação e melhoramento do meio ambiente. (PIOVESAN, 2000, p. 428).

O Estado Brasileiro observou de maneira irrestrita esses documentos, na medida em que aduz no caput, do art. 225 da Constituição Federal em vigor que: Todos tem direito a um meio ecologicamente equilibrado [...].

Sob o enfoque da sustentabilidade ambiental, da necessidade do uso racional dos recursos naturais limitados, podemos refletir sobre a relação entre a ideia de sustentabilidade e desenvolvimento. Assim, nossa tarefa, neste momento, é esclarecer o que entendemos e o que deve ser compreendido por desenvolvimento. 
Segundo Theis (2006), as metamorfoses que se operam no campo do desenvolvimento guardam estreita relação com o clima ideológico e com as condições históricas predominantes em cada época histórica.

Por essa razão, desenvolvimento não é algo que possa ser testado num laboratório desconectado do tempo e do espaço, pelo contrário, como Altvater (1992) assegurou, é um processo complexo que tem lugar precisamente num dado espaço social e natural e num certo tempo histórico. (THEIS, 2006, p.29).

Com segurança, podemos afirmar que o desenvolvimento é um processo complexo que tem lugar num espaço social e natural e num tempo histórico,

\begin{abstract}
se esse desenvolvimento no contexto do capitalismo liberalprodutivista encobre as relações perversas que predominam no interior da sociedade e entre esta e o meio físico; e se esse desenvolvimento é condicionado pela presente desordem global, o que resta a fazer senão assistir passivamente à desordem global ganha dimensões que recoloquem no horizonte a alternativa da barbárie? (THEIS, 2006, p.30).
\end{abstract}

Por evidente, não podemos abrir mão do nosso grau civilizacional, após séculos de lutas e conquistas no campo das ciências sociais, médicas, jurídicas ou tecnológicas. Neste ponto, é importante que o desenvolvimento não seja confundido com o crescimento econômico. Isto porque o desenvolvimento é um processo integrado em que as estruturas sociais, jurídicas e tecnológicas do Estado passam por transformações, que objetivam à melhora da qualidade de vida dos homens e mulheres que habitam em determinado espaço. $O$ crescimento econômico não pode estar apoiado na alteração adversa da qualidade de vida e do ambiente ecologicamente equilibrado.

Assim, a ideia de desenvolvimento deve vir a questionar os valores da sociedade capitalista e consumista como a nossa e, em geral, rejeitar a economia produtora de valores de troca e predadora de recursos naturais não renováveis. Torna-se essencial, para o nosso tempo, repensarmos alternativas econômicas que apresentem, também, viabilidade ambiental e que o desenvolvimento possa dar-se em todas as suas dimensões, sejam elas: social, cultural, ecológica, espacial e econômica. Mas, como explicar o incremento da complexidade que envolve as relações de apropriação de bens naturais, produção e consumo em uma sociedade dita de consumo, como a nossa? Como conter ou redirecionar a apropriação e a utilização de recursos ambientais, em especial os não renováveis?

E a sustentabilidade ambiental? Onde localizá-la nos processos sociais e/ou como aplicá-la em nossos contextos?

Em primeiro lugar, precisamos considerar que a sustentabilidade é um princípio válido para todos os recursos renováveis, isto é, somente trataremos de sustentabilidade ambiental para os processos de apropriação e transformação de recursos ambientais renováveis. Tal posição remete-nos à não aplicação desse princípio com relação os recursos ambientais não renováveis ou às atividades que produzem danos ambientais irreversíveis. 
Outra questão pertinente diz respeito à implementação do desenvolvimento sustentável que requer uma justa distribuição das riquezas dentro dos países e entre os países, o que não se observa nos contextos econômicos, sociais da atualidade. Destarte, a realização desse princípio está calcada em valores materiais (proporcionalidade econômica) e a uma coordenação de ordem moral e ética (proporcionalidade axiológica, voltada aos princípios e aos valores existentes na sociedade), conforme pontua Derani (1997). Daí, decorre a imensa dificuldade de implementação da ideia de sustentabilidade ambiental entendida como princípio norteador do direito ao desenvolvimento progressivo dos povos.

Talvez a tentativa de construção de respostas para as essas questões anteriormente formuladas possa iniciar-se por meio da análise da teoria das necessidades.

\title{
3 A TEORIA DAS NECESSIDADES E A SUBMISSÃO DA NATUREZA
}

Neste tópico, nossa atenção centra-se nos estudos de Agnes Heller (1996) no que se refere à Teoria das necessidades em Marx. Segundo a filósofa húngara, que, inicialmente, teve a sua trajetória acadêmica intelectual ligada ao marxismo, o qual abandonou gradativamente ao longo dos tempos, em Manuscritos econômico-filosóficos, Marx admite que o sistema das necessidades constitui uma expressão da alienação capitalista, em que o fim da produção não é a satisfação do que aparece como necessário, mas a valorização do capital. Dessa forma, o problema está na fetichização dessas necessidades pelo capitalismo, que as transforma num mero número e as multiplica, pois essas necessidades não desaparecem, como levava a crer a utopia marxiana. Ao conceito de necessidades alienadas, Marx opõe o de necessidades radicais, que são as que possuem um caráter qualitativo.

\begin{abstract}
Em referencia al valor presente del concepto de necessidades y necessidades

radicales, todavia distingo entre necessidades cuantificables y no cuantificables. Y todavía hablo de necessidades radicales (que son aquellas no cuantificables en principio) pero ya no desde el entramado de una gran narrativa, tal como hice em La teoría de las necesidades en Marx. Por tanto, todavía creo en el valor del concepto de necesidades frente al de intereses o preferencias. Si se precisa de una analogía que lo aclare, los intereses están relacionados con aquello que Heidegger denominó Gestell, mientras que las necesidades que no pueden convertir-se en intereses "no pueden cuantificar-se, y en este sentido son abiertas". (HELLER, 1996, p.56).
\end{abstract}

No capitalismo, as necessidades foram fetichizadas pela mercantilização. São os homens que servem à produção, não a produção que serve aos homens; por isso, referimos que os indivíduos, no sistema capitalista, produzem de forma e maneira desmedida. Para Heller (2002), a produção não tem por objetivo a satisfação das necessidades humanas, mas a busca da valorização do capital. E, uma relação fetichizada é uma relação alienada, visto que há um feitiço na mercadoria que leva os indivíduos a uma contínua e constante insatisfação, conduzindo-se a desenvolver a ideia de 
sociedade insatisfeita:

\begin{abstract}
A idéia de 'sociedade insatisfeita' busca captar a especificidade de nossa época mundial da perspectiva das necessidades ou, mais particularmente, da criação, percepção, distribuição e satisfação das necessidades. Isso sugere que a forma moderna de criação, percepção e distribuição de necessidades reforça a insatisfação, independente de alguma necessidade concreta ser ou não de fato satisfeita. (HELLER, 2002, p. 29).
\end{abstract}

Nessa análise, há três lógicas desenvolvimentistas distintas na Modernidade ocidental - a industrialização, o capitalismo e a democracia - e o progresso de cada uma exige a força motivacional da insatisfação. Por isso, no atual contexto ocidental, se as pessoas sentirem-se satisfeitas, a sociedade moderna não poderá mais se reproduzir. Há uma lógica de desenvolvimento centrada na ideia de que a satisfação de algumas necessidades leva, automaticamente, à busca de satisfação de outras, porque, ao contrário do que, inicialmente, se imaginava, a satisfação das necessidades conduz à busca por outras antes inexistentes. As necessidades, "novas necessidades", estão sendo criadas a todo o momento.

A satisfação na presente geração de algumas necessidades que ficaram insatisfeitas numa anterior não vão fazer a insatisfação diminuir ou cessar. [...] Pois maiores esperanças mudam a qualidade e a quantidade das necessidades, e os filhos medem sua experiência por suas próprias esperanças, e não pelas dos seus pais. (HELLER, 2002, p. 36)

O surgimento constante de novas necessidades dá-se pela insatisfação, que propulsiona o desenvolvimento da modernidade ocidental. O interessante é que a própria sociedade, ao ver satisfeitas algumas de suas necessidades, justifica, pela insatisfação, a necessidade de realização e satisfação das "novas necessidades" (que estão sendo criadas a todo o instante), porque, insatisfeita, vive mudando continuamente. $\mathrm{E}$ a força motivacional que perpetua as três lógicas da Modernidade ocidental (industrialização, capitalismo e democracia) é as carências. "A industrialização e o capitalismo oferecem meios de satisfação de carências" (HELLER, 2002, p.55), concomitantemente à criação de novas carências.

Para Heller (1996), todas as necessidades são reais, não sendo adequado tratar-se de necessidades verdadeiras ou necessidades falsas. Adotado o ponto de vista de que todas as necessidades são reais e que há um número infinitamente grande de necessidades a serem satisfeitas, devemos considerar que nem todas são possíveis de satisfação em razão das dinâmicas atuais e das condições presentes na sociedade. Isso se dá-se em virtude das desigualdades sociais; como consequência, devemos eleger prioridades. Destarte, Heller (1996, p. 61), ao identificar as inúmeras necessidades existentes no conjunto social num determinado contexto, com algumas maiores que outras, refere que, sendo todas necessidades reais, é adequado acionar (ou resolver tal dilema) o sistema de prioridade de satisfação de determinadas necessidades por meio do debate público e democrático. Portanto, as carências e as necessidades criadas, pelo/ou no grupo social, tornam-se 
demandas a serem satisfeitas.

Há quem entenda que os liberais defenderam que as necessidades seriam ilimitadas e, portanto, impossíveis de serem satisfeitas. A industrialização teria trazido consigo a possibilidade de abundância na produção e no consumo tanto para a satisfação de necessidades básicas quanto das derivadas, contudo, também acrescentou a escassez ou 0 esgotamento dos recursos naturais essenciais ao processo produtivo ( o que provoca a valorização do capital, pois toda escassez leva à valorização do objeto escasso).

\begin{abstract}
A busca da satisfação das necessidades é o que leva à produção dos meios para satisfazê-las, criando o que Marx designa como 'primeiro ato histórico'. Primeiro é preciso viver, ou seja, 'comer, beber, ter habitação, vestir-se e algumas coisas mais', mas logo em seguida, acrescenta Marx, 'satisfeita esta primeira necessidade, a ação de satisfazê-la e o instrumento de satisfação já adquirido conduzem a novas necessidades' - e esta produção de novas necessidades é o primeiro ato histórico. (CARNEIRO, 2002, p. 118).
\end{abstract}

Podemos afirmar que, para a teoria marxista, a ampliação das necessidades faz parte de um processo de crescimento material e cultural em que a humanidade reinventa-se a si própria por meio do trabalho, que passa também a ser uma necessidade. Isto é, no processo histórico, os indivíduos, pelas suas interações com o meio, reinventam-se, criam suas (novas) necessidades, num processo que não cessa, é constante e permanente.

Considerando que, para Marx, todas as formas de produção (força humana de trabalho) são uma exteriorização da força natural, há que se mencionar a constante e contínua troca que se estabelece entre o homem e a natureza. ${ }^{4}$ Diante dessa dinâmica social, de criação constante de necessidades, torna-se difícil implementar, na prática cotidiana, um modelo ou modelos de desenvolvimento que sejam pautados pela concepção de sustentabilidade ambiental. Por fim, a equação que pede resolução é um tanto complexa, isso porque a garantia e a segurança da observância ao direito humano fundamental que todos têm direito ao meio ecologicamente equilibrado passam, necessariamente, pelo direito dos povos ao desenvolvimento econômico, social e cultural, em que a lógica não deve ser apenas a acumulação de bens e valores, mas principalmente a preservação e a conservação ambientais.

Em uma sociedade de consumo, é impossível produzir com o objetivo de esgotar-se as necessidades, pois elas, a todo o momento, estarão sendo recriadas, tendo em vista que o modo de consumir é produzido pela produção de forma objetiva e subjetiva, como já mencionado, e o desenvolvimento da atividade econômica significa consumo de recursos ambientais. Dessa forma, há que pensarmos em uma forma, ou fórmulas, de resolução da complexa equação composta pela proposta de desenvolvimento econômico progressivo dos povos e a sustentabilidade ambiental. A proposição é pensarmos em uma maneira de diminuir o consumo de recursos ambientais não renováveis, sem 
que essa redução afete o desenvolvimento econômico.

Expresso de outra maneira, o desenvolvimento econômico encontra (ou deveria encontrar) seus próprios limites na prática de conservação e preservação dos recursos naturais e, como isso implica, em tese, na existência de uma proporcionalidade econômica e axiológica em nossa sociedade, o direito ambiental, entendido como o conjunto de normas e regras, cria restrições e prevê sanções para exigir a observância de comportamentos que não são observados automaticamente pelo conjunto social. Neste caso, na veemência e na defesa dos chamados direitos e interesses de natureza difusa aliados na concretização do direito humano que todos têm de viver em um ambiente ecologicamente equilibrado.

As respostas aos questionamentos e aos conflitos ambientais de nosso tempo precisam ser pensadas pelo direito e ainda estão em processo embrionário de formulação.

\section{ENVIRONMENTAL LAW AND SUSTAINABILITY}

\section{ABSTRACT}

This paper aims to present some of the factors that led to the emergence and consolidation of environmental law on the socio-legal Brazilian, from the emergence of transindividual interests and recognition of the legal environment as well. Considers, moreover, the overlapping area of environmental law with the right to development and the idea of environmental sustainability, both understood as fundamental rights, and proposes some reflections from the analysis of the theory of needs.

Keywords: Environmental Law. Sustainability. Theory of needs.

\section{NOTAS}

\footnotetext{
1. Doutora em Ciências Sociais pela Universidade do Vale dos Sinos - Unisinos, professora da Graduação e Pós-Graduação da Faculdade de Direito da Universidade de Passo Fundo - UPF, Coordenadora do Pós-Graduação em Direito da UPF; Membro do Comitê de Ética em Pesquisa da UPF - CEP/UPF, Membro do Centro de Ciências e Tecnologias Ambientais CCTAM/ UPF; professora convidada do Programa de Mestrado em Desenvolvimento da Universidade Regional do Noroeste do Estado do Rio Grande do Sul - UNIJUÍ, Advogada. Email: elenisefs@upf.br ou elenisefs.adv@gmail.com.

2. Texto apresentado em aula aos mestrandos em Direito Agrário do Programa de Mestrado em Direito Agrário da Universidade Federal de Goiás - UFG, em 13/05/2011.

3. GEE - gases de efeito estufa.

4. En el trabajo el hombre "se contrapone, como poder natural, a la materia de la naturaleza". "En tanto el hombre [...] actúa exteriormente sobre la naturaleza y la modifica, modifica al mismo tiempo a su propia naturaleza". La dialéctica de sujeto y objeto es para Marx una dialéctica de las partes constitutivas de la naturaleza." (SCHMIDT, 1983, p. 12).
}

\section{REFERÊNCIAS}

REVISTA DO DIREITO UNISC, SANTA CRUZ DO SUL № 36|P. 17-28| JUL-DEZ 2011 
BRASIL. Lei n. 8.078, de 11 de setembro de 1990. Dispõe sobre o Código de Defesa do Consumidor. Coletânea de legislação ambiental e Constituição Federal. Odete Medauar (org.). 6. ed. São Paulo: RT, 2011 a.

. Constituição da República Federativa do Brasil de 1988. Dispõe sobre o Código de Defesa do Consumidor. Coletânea de legislação ambiental e Constituição Federal. Odete Medauar (org.). 6. ed. São Paulo: RT, 2011b.

BOBBIO, Norberto. A era dos direitos. Rio de Janeiro: Campus, 1992.

CARNEIRO, Henrique. As necessidades humanas e o proibicionismo no século XX. Outubro, São Paulo, n. 6, p. 118, 2002.

COMPARATO, Fábio Konder. Fundamentos dos Direitos Humanos, Cultura dos Direitos Humanos. São Paulo: ed. LTr, 1998.

DERANI, Cristiane. Direito ambiental econômico. São Paulo: Max Limonad, 1997.

HELLER, Agnes. Una revisión de la teoría de las necesidades. Barcelona: Ediciones Paidós. I.C.E. de la Universidad Autónoma de Barcelona, 1996.

HELLER, Agnes; FEHÉR, Ferenc. A condição política pós-moderna. Rio de Janeiro: Civilização Brasileira, 2002.

MARX, Karl. Manuscritos Econômico-Filosóficos. São Paulo: Editora Martin Claret, 2006.

PIOVESAN, Flávia. Direitos humanos e o direito constitucional internacional. São Paulo: Max Limonad, 2000.

SACHS, Ignacy. Desenvolvimento, Direitos Humanos e Cidadania. In: Direitos Humanos no Século XXI, 1998.

SÉGUIN, Elida. Direito ambiental: nossa casa planetária. Rio de Janeiro: Forense, 2002.

SCHMIDT, Alfred. El concepto de naturaleza en Marx. Madrid: Siglo Veintiuno Editores, 1983.

THEIS, Ivo M. Desenvolvimento, meio ambiente, Território: qual sustentabilidade? In: Desenvolvimento em questão. Revista do Programa de Pós-Graduação em Desenvolvimento. Universidade Regional do Noroeste do Estado do Rio Grande do Sul. Ano 1, n. 1 (jan./jun. 2003). ljuí: Ed. Unijui, 2003. v. 8. Jul/dez. 2006, p. 13-34.

Recebido para publicação: 27/07/2011

Aceito para publicação: 23/12/2011

REVISTA DO DIREITO UNISC, SANTA CRUZ DO SUL № 36|P. 17-28| JUL-DEZ 2011 